\title{
Green Synthesis and Evaluation of Antimicrobial Activity of Silver Nanoparticles from Hydrophila auriculata Leaf Extract
}

\author{
M. Ravishankar*, V. Christibai Juliet Ester \\ Department of Chemistry, Rajah Serfoji Government College, Thanjavur - 613 005, Tamil Nadu, India.
}

\section{ARTICLE DETAILS}

Article history:

Received 20 April 2018

Accepted 04 May 2018

Available online 16 May 2018

\section{Keywords:}

Hydrophila auriculata

Silver Nanoparticles

Anti-Inflammatory Activity

\begin{abstract}
A B S T R A C T
Nanochemistry is relatively a new area of science arisen in the last decade of past century after discovery of fullerenes and nanotubes. Metal nanoparticles can be prepared by physical, chemical and biological routes; the first one is a physical approach that utilizes several methods such as evaporation/ condensation and laser ablation. Various metals like copper, titanium, gold, silver and iron were used for the synthesis of nanoparticles. Among the noble metals, silver nanoparticles have become the focus of intensive research due to its wide range of applications for many sectors of life and Industry. In this work, we describe a cost effective and environment friendly technique for green synthesis of silver nanoparticles from $1 \mathrm{mM} \mathrm{AgNO}_{3}$ solution through the extract of Hydrophila auriculata leaf as it is acts as a reducing as well as capping agent. Nanoparticles were characterized using UV-Vis absorption spectroscopy and SEM analysis showed the average particle size range10-40 nm with higher density polydispersed spherical in shape. The synthesized silver nanoparticles exhibited potential antiinflammatory activity.
\end{abstract}

\section{Introduction}

Nanochemistry is relatively a new area of science arisen in the last decade of past century after discovery of fullerenes and nanotubes. It is introduced into more extent interdisciplinary integrated modern science now known as rapidly developing nanotechnology [1]. Nanotechnology is becoming an innovative area of increasing research and industrial interest since the1980's. Nanotechnology can be defined as the manipulation of atom by atom from the material world by the combination of engineering, chemical and biological approaches. In the past decade, considerable attention has been paid for the development of novel strategies for the synthesis of different kind of nano-objects. Most of the current strategies are usually worked by the use of physical or chemical principles to develop a variety of nano-objects with multiple applications. Main fields of nanotechnology applications range from catalysis, micro- and nanoelectronics (semiconductors, single electrons transistors), non-linear optic devices, photo-electrochemistry to biomedicine, diagnostics, foods and environment, chemical analysis and others [2].

Metal nanoparticles can be prepared by physical, chemical and biological routes; the first one is a physical approach that utilizes several methods such as evaporation/condensation and laser ablation. The second one is a chemical approach in which the metal ions in solution are reduced in conditions favoring the subsequent formation of small metal clusters or aggregates [3]. Various metals like copper, titanium, gold, silver and iron were used for the synthesis of nanoparticles. Among the noble metals, silver nanoparticles have become the focus of intensive research due to its wide range of applications for many sectors of life and industry [4]. Recently, biosynthetic methods employing naturally occurring reducing agents such as polysaccharides, biological microorganism such as bacteria and fungus or plants extract, i.e. green chemistry, have emerged as a simple and viable alternative to more complex physical and chemical synthetic procedures to obtain AgNP's [5].

In the recent decades, increased development of green synthesis of nanoparticles is inevitable because of its incredible applications in all fields of science. There were numerous work have been produced based on the plant and its extract mediated synthesis of nanoparticles. AgNP's has been synthesized by using the plant broth from a wide variety of plants such as Catharanthus roseus [6] and Bacopa monnieri [7]. Keeping in view, in the present study aimed to explore the novel approaches for the biosynthesis of silver nanoparticles using Hydrophila auriculata leaf and also evaluate the anti-inflammatory activity of the synthesised AgNP's.

\section{Experimental Methods}

\subsection{Chemicals}

All the experiments were conducted at room temperature. Materials used for the synthesis of silver nanoparticles were AR grade silver nitrate $\left(\mathrm{AgNO}_{3}\right)$ purchased from Merck, India.

\subsection{Collection of Hydrophila auriculata Leaves}

The Hydrophila auriculata leaves were collected in January 2015 from Kurungalam Village, Thanjavur district, Tamil Nadu from a single herb. The leaves were identified and authenticated by Dr. S. John Britto, Director, Rapiant Herbarium and Centre for Molecular Systematics, St. Joseph's college, Trichy, Tamil Nadu. India. A voucher specimen has been deposited at the Rabinat Herbarium, St. Josephs College, Trichy, Tamil Nadu, India.

\subsection{Preparation of Leaf Extract}

The dried leafs were pulverized well with mortar and pestle to make a powder. Twenty grams of powder sample was mixed with $100 \mathrm{ml}$ of deionized water and the mixture was boiled for $10 \mathrm{~min}$. After cooling the leaf extract was filtered with Whatman No. 1 filter paper. The filtrate was stored at $4{ }^{\circ} \mathrm{C}$ for further use.

\subsection{Synthesis of Ag Nanoparticles using Leaf Extracts}

For the Ag nanoparticles synthesis, $5 \mathrm{~mL}$ of Hydrophila auriculata leaf extract was added to $45 \mathrm{~mL}$ of $1 \mathrm{mM}$ aqueous $\mathrm{AgNO}_{3}$ solution in a $250 \mathrm{~mL}$ Erlenmeyer flask. The flask was then incubated in dark $5 \mathrm{~h}$ (to minimize the photo activation of silver nitrate), at room temperature. A control setup was also maintained without leaf extract. The Ag nanoparticle solution thus obtained was purified by repeated centrifugation at 10,000 rpm for $15 \mathrm{~min}$ followed by re-dispersion of the pellet in de-ionized water. Then the Ag nanoparticles were dried for using SEM analysis [8]. 


\subsection{UV-Vis and FTIR Spectra Analysis}

The reduction of pure $\mathrm{Ag}^{+}$ions was monitored by measuring the UV-Vis spectrum of the reaction medium for 5 hours after diluting a small aliquot of the sample into distilled water. UV-Vis spectral analysis was done by using UV-Vis spectrophotometer UV-2450 (Shimadzu). The resulting pellet is dissolved in deionized water and filtered through Whatman filter paper No: 42. An aliquot of this filtrate containing silver nanoparticles were used for Fourier transmission infrared spectroscopy (FTIR).

\subsection{SEM Analysis of Silver Nanoparticles}

Scanning electron microscopic (SEM) analysis was done using ZEISS machine. Thin films of the sample were prepared on a carbon coated copper grid by just dropping a very small amount of the sample on the grid. Extra solution was removed using a blotting paper and then the films on the SEM grid were allowed to dry by placing it under a mercury lamp for 5 $\min$.

\subsection{Antimicrobial Activity}

Antimicrobial activity was determined using disc diffusion method [9, 10]. The overnight inoculated bacterial cultures were spread over the freshly prepared Muller-Hinton agar plates. Petri plates were prepared by pouring $30 \mathrm{~mL}$ of nutrient agar /potatoes dextrose agar medium for bacteria/fungi. A sterile cotton swab is dipped into standardized bacterial strains of Staphylococcus aureus, Escherichia coli were spread on solidified nutrient agar plate whereas fungi strains Candida albicans and Aspergillus flavus was spread on solidified potato dextrose agar and allowed to dry for 10 minutes. Using sterile forceps, the sterile filter papers ( $6 \mathrm{~mm}$ diameter) containing the sample solutions $(30 \mu \mathrm{L})$ and standard $(30 \mu \mathrm{L})$ were laid down on the surface of inoculated agar plate. The plates were incubated at $37{ }^{\circ} \mathrm{C}$ for $24 \mathrm{~h}$ for the bacteria $(30 \pm 1)$ whereas $24-48 \mathrm{~h}$ for fungi strains. Each sample was tested in triplicates. The chloramphenicol (bacteria) and fluconazole (fungi) disc (reference discs) also kept on the same plate incubated at $37^{\circ} \mathrm{C}$ for $24 \mathrm{~h}$ and after incubation the zone of inhibition was measured.

\section{Results and Discussion}

\subsection{Synthesis of Silver Nanoparticles}

The synthesis of silver nanoparticles through leaf extracts were carried out. Leaf extract is used as reducing agent for its distinctive properties with catalytic and chemical stability. Applications of such eco-friendly nanoparticles in bactericidal, wound healing and other medical and electronic applications, makes this method potentially exciting for the large-scale synthesis of other inorganic materials (nanomaterials). The aqueous silver ions when exposed to herbal extracts were reduced in solution, there by leading to the formation of silver hydrosol. The time duration of change in colour varies from plant to plant. The phytochemicals present in the leaf extract were considered responsible for the reduction of silver ions. It is also well known that silver nanoparticles exhibit yellowish - brown colour in aqueous solution due to excitation of surface plasma vibrations in silver nanoparticles The appearance of yellowish-brown colour (Fig. 1) in the reaction vessels suggest the formation of silver nanoparticles (SNPs) [11].

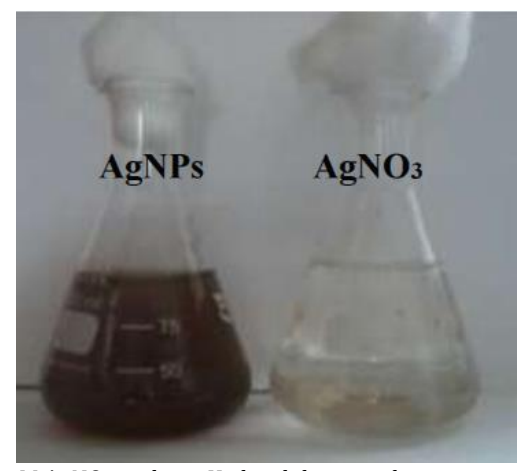

\footnotetext{
$\mathrm{AgNO}_{3}=1 \mathrm{mM} \mathrm{AgNO}_{3}$ without Hydrophila auriculata extract.

AgNPs $=1 \mathrm{mM} \mathrm{AgNO}_{3}$ with Hydrophila auriculata leaf extract after $5 \mathrm{~h}$ of incubation (Brown colour)
}

Fig. 1 Formation of brown colour after addition of $\mathrm{AgNO}_{3}$ indicate synthesis of AgNPs in the process of reduction of $\mathrm{Ag}^{+}$to $\mathrm{Ag}$ nanoparticles and control $\left(\mathrm{AgNO}_{3}\right)$

\subsection{UV-Vis and FTIR Spectra Analysis}

It is generally recognized that UV-Vis spectroscopy could be used to examine the size and shape-controlled nanoparticles in aqueous https://doi.org/10.30799/jnst.116.18040303 suspensions. Fig. 2 shows the UV-Vis spectra recorded for the reaction medium after 5 hours. The UV-Vis spectra of the reaction mixture of silver nitrate solution with Hydrophila auriculata leaf extract shoed peaks at 420 $\mathrm{nm}$ indicate the presence of silver nanoparticles which is synthesized by Hydrophila auriculata extract; The peak was raised due to the effect of surface plasmon resonance of electrons in the reaction mixture and the broadening of peak indicated that the particles are polydispersed. Appearance of this peak assigned to a surface plasmon, is welldocumented for various metal nanoparticles with size ranging from $2 \mathrm{~nm}$ to $100 \mathrm{~nm}$ [12].

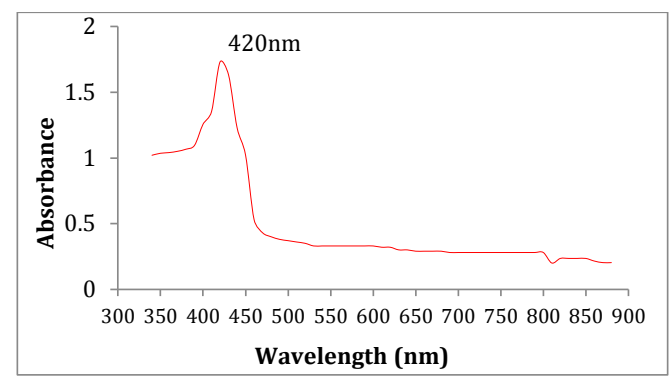

Fig. 2 UV-Vis absorption spectrum of silver nanoparticles synthesized by treating 1 $\mathrm{mM}$ aqueous $\mathrm{AgNO}_{3}$ solution with Hydrophila auriculata leaf extract after 5 hours

FTIR is an important tool which enables us to understand the involvement of functional groups in the interactions between metal particles and biomolecules. In the present work, FTIR spectra was used for the identification of biomolecules responsible for capping and stabilizing the silver nanoparticles. The FTIR spectra of the Hydrophila auriculata is given in the Fig. 3 and Table 1. FTIR spectrum of Hydrophila auriculata extract shows peak at 3304.30, 2775.70, 1651.23, 1405.37, 1313.70 and 674.69. The band appeared at about $1405 \mathrm{~cm}^{-1}$ can be assigned the aromatic rings. The strong broad band appearing at $3304 \mathrm{~cm}^{-1}$ can be associated to the stretching vibrations of alcoholic and phenolic $\mathrm{O}-\mathrm{H}$. At peak at $2775 \mathrm{~cm}^{-1}$ that could be assigned aldehyde to $\mathrm{H}-\mathrm{C}=\mathrm{O}: \mathrm{C}-\mathrm{H}$ stretch group. Therefore, from the results of FTIR analyses of extract mediated synthesised of silver nanoparticles it can be concluded that some of the biological molecules of leaf extract such as alkaloids, phenols, flavonoids, amino acids, glycosides, and tannins are responsible for the biotransformation of silver ions to silver nanoparticles and its stabilization in aqueous medium. This results were good agreement with the earlier reports $[13,14]$.

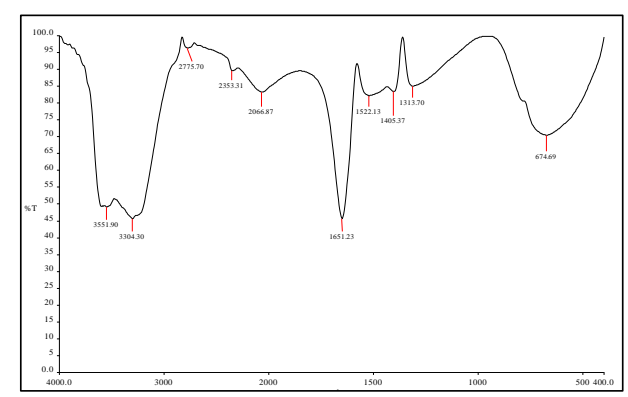

Fig. 3 FTIR analysis of silver nanoparticles synthesized by treating $1 \mathrm{mM}$ aqueous $\mathrm{AgNO}_{3}$ solution with Hydrophila auriculata extract

Table 1 FTIR analysis of silver nanoparticles synthesized by treating $1 \mathrm{mM}$ aqueous $\mathrm{AgNO}_{3}$ solution with Hydrophila auriculata extract

\begin{tabular}{lll}
\hline Peak & Bond & Functional group \\
\hline 3304.30 & O-H Stretch, H-Bonded & Alcohols, Phenols \\
2775.70 & H-C=O: C-H Stretch & Aldehydes \\
1651.23 & C=C- Stretch & Alkenes \\
1405.37 & C-C Stretch (In-Ring) & Aromatics \\
1313.70 & C-N Stretch & Aromatic Amines \\
674.69 & =C-H Bend & Alkenes \\
\hline
\end{tabular}

\subsection{Scanning Electron Microscope (SEM)}

The surface morphology, size and shape of the silver nanoparticles were analyzed by Scanning Electron Microscope. Fig. 4 shows the SEM image of silver nanoparticles synthesized from leaf extract. The SEM images show individual silver nanoparticles which are of higher density polydispersed spherical in shape as well as number of aggregates with no defined morphology. The presences of biomolecules in the leaf extract has resulted in the synthesis of spherical silver nanoparticles and the aggregation may be due to the presence of secondary metabolites in the leaf extract. The SEM image shows the size of the silver nanoparticles ranging from 10 to 
$60 \mathrm{~nm}$. Similar result of the silver nanoparticles size was reported by using Hydrophila auriculata leaf extract [15].

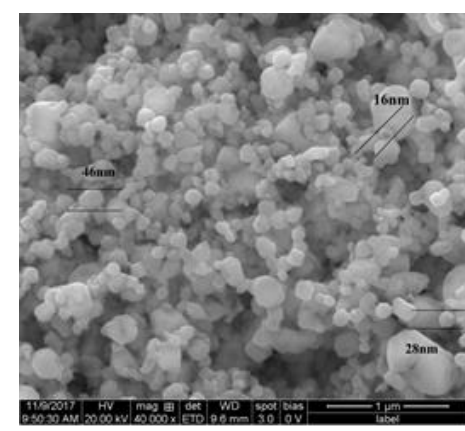

Fig. 4 High resolution scanning electron microscopic (SEM) image of silver nanoparticles (AgNPs) ranged between $10-60 \mathrm{~nm}$

\subsection{Antimicrobial Activity}

The AgNP's of Hydrophila auriculata leaf shows highest antibacterial activity was observed against E. coli, S. aureus, Candida albicans and Aspergillus flavus. The inhibitory activities in culture media of the Ag nanoparticles reported in Table 2 and Fig. 5 were comparable with standard antimicrobiotic viz. chloramphenicol and fluconazole. When Ag nanoparticles were tested they effectively inhibited microbial growth. The results show that Ag nanoparticles having antimicrobial activity against $E$. coli that was similar as observed by Sondi and Salopek-Sondi [16].

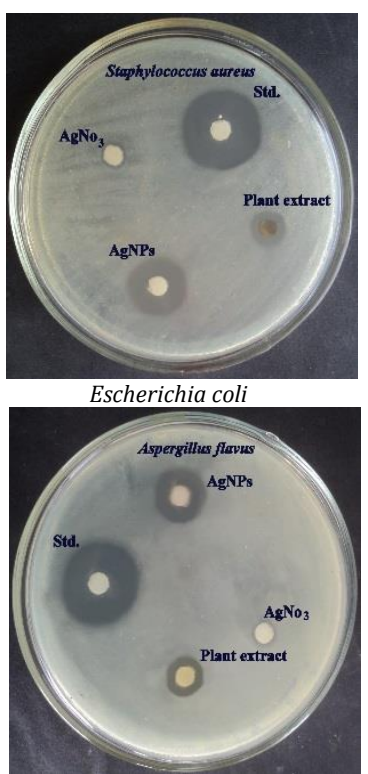

Candida albicans
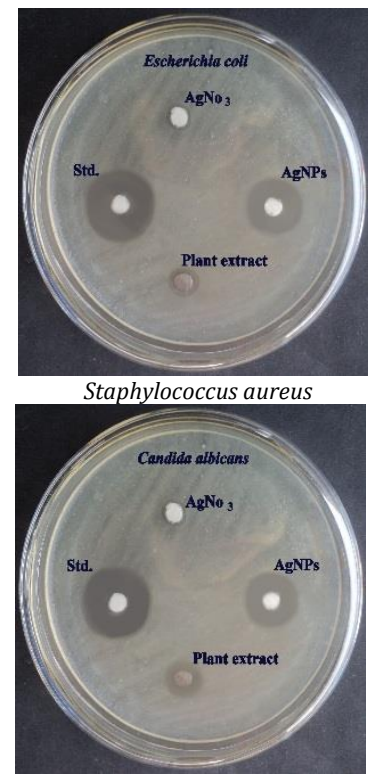

Aspergillus flavus
Fig. 5 Antibacterial activity of Hydrophila auriculata AgNPs

Table 2 Antimicrobial activity of Hydrophila auriculata AgNPs $(30 \mu \mathrm{L})$

\begin{tabular}{lcccc}
\hline Microorganisms & $\mathrm{AgNo}_{3}$ & \multicolumn{2}{l}{ Plant extract AgNPs } & Standard \\
\hline Bacteria & & & & \\
Escherichia coli $(\mathrm{mm})$ & $0.30 \pm 0.02$ & $0.50 \pm 0.03$ & $6.20 \pm 0.43$ & $9.10 \pm 0.63$ \\
Staphylococcus aureus $(\mathrm{mm})$ & $0.20 \pm 0.01$ & $1.50 \pm 0.10$ & $5.70 \pm 0.39$ & $9.40 \pm 0.65$ \\
Fungal & & & & \\
Candida albicans $(\mathrm{mm})$ & $0.10 \pm 0.01$ & $0.80 \pm 0.05$ & $5.40 \pm 0.37$ & $8.80 \pm 0.61$ \\
Aspergillus flavus $(\mathrm{mm})$ & $0.20 \pm 0.01$ & $1.10 \pm 0.07$ & $5.20 \pm 0.36$ & $9.00 \pm 0.63$ \\
\hline \multicolumn{4}{l}{ Values were expressed as Mean \pm SD } \\
Bacterial standard : Chloramphenicol; Fungal standard: Fluconazole
\end{tabular}

The silver nanoparticles attached to the surface of the cell membrane troubling the permeability and respiration functions followed by dysfunction of metabolic pathways including, $\mathrm{Ag}+$ can interact with nucleic acids they preferentially interact with the bases in the DNA rather than with the phosphate functional groups. Thereby, inhibiting the cell division and also damaged the cell envelope and cellular contents of the bacteria [17]. However, the interaction between the components of outer cell membrane and AgNPs is not understood. It is well established that $\mathrm{Ag}^{+}$ and $\mathrm{Ag}^{-}$ions founded compounds have strong antimicrobial activity; several researchers are keen in using other inorganic nanoparticles as antibacterial agents $[18,19]$. In another study, the mechanism of silver nanoparticles against bacterial cells due to the shape and size of the bacterial cells increased, and the cytoplasmic membrane, contents, and outer cell layers exhibited structural abnormalities [20].

\section{Conclusion}

Medicinal plants have medically important compounds in their different parts. The synthesis of nanoparticles using plants depends on the nature of plant such as its phytochemical content, special adaptation, and medicinal importance. In this study, we investigated eco-friendly and costeffective green synthesis of silver nanoparticles using leaf extract of medicinal plant Hydrophila auriculata. Water soluble organic compounds present in the leaf extract was mainly responsible for synthesis of silver nanoparticles by reducing silver ions to nanosized silver particles. The UVvisible spectroscopy, FTIR and SEM studies of the synthesized silver nanoparticles elucidated that the silver nanoparticles were crystalline in nature, spherical in shape with size ranging between 10 and $60 \mathrm{~nm}$ and stable. The synthesized silver nanoparticles exhibited antimicrobial activity. This finding suggests that the synthesised AgNPs using Hydrophila auriculata leaf extract could be a good source for developing green nanomedicine for the infectious diseases.

\section{References}

[1] A.L. Buchachenko, Nanochemistry: a direct route to high technologies of the new century, Rus. Chem. Rev. 72(5) (2003) 375-391.

[2] C.I. Contescu, K. Putyera, Nanoscience and nanotechnology, Dekker Encyclo. Nanosci. Nanotechnol. 1-8 (2009) 256-300.

[3] G. Khomutov, S. Gubin, Antimicrobial activity of silver nanoparticles synthesized by using medicinal plants, Mater. Sci. Eng. 22 (2002) 141-144

[4] A.A. El-Kheshen, S.F. Gad El-Rab, Effect of reducing and protecting agents on size of silver nanoparticles and their anti-bacterial activity, Der. Pharma. Chemica. 4(1) (2012) 53-65.

[5] M. Amanullah, L. Yu, Green synthesis of silver naoparticles, J. Petrol Sci. Eng. 48 (2005) 199-203.

[6] K.S. Mukunthan, E.K. Elumalai, N.P. Trupti, V. Ramachandra Murty, Catharanthus roseus: a natural source for the synthesis of silver nanoparticles, Asian Pacific J. Trop. Biomed. 8 (2011) 270-274.

[7] C. Krishnaraj, E.G. Jagan, R. Ramachandran, S.M. Abirami, N. Mohan, P.T Kalaichelvan, Effect of biologically synthesized silver nanoparticles on Bacopa monnieri, (Linn.) Wettst. Plant growth metabolism, Proces. Biochem. 47 (2012) 651-658.

[8] R. Arunachalam, S. Dhanasingh, B. Kalimuthu, M. Uthirappan, Chellan Rose, A.B. Mandal, Phytosynthesis of silver nanoparticles using Coccinia grandis leaf extract and its application in the photocatalytic degradation, Colloids Surf. B: Biointerf. 94 (2012) 226-230.

[9] NCCLS, Standards for antimicrobial disc susceptibility tests, National Committee for Clinical Laboratory Standards, Performance PA: NCCLS Publications, Pennsylvania, 1993.

[10] O. Awoyinka, I.O. Balogun, A.A. Ogunnowo, Phytochemical screening and in vitro bioactivity of Cnidoscolus aconitifolius (Euphorbiaceae), J. Med. Plant Res. 1(3) (2007) 63-65.

[11] A. Thirumurgan, N.A. Tomy, R. Jai Ganesh, S. Gobikrishnan, Biological reduction of silver nanoparticles using plant leaf extracts and its effect an increased antimicrobial activity against clinically isolated organism, Der. Phar. Chem. 2 (2010) 279-284.

[12] A. Henglein, Physicochemical properties of small metal particles in solution: "microelectrode" reactions, chemisorption, composite metal particles, and the atom-to-metal transition, J. Phys. Chem. B 97 (1993) 5457-5462.

[13] B. Manimegalai, S. Velavan, Green synthesis of silver nanoparticles using Azima tetracantha leaf extract and evaluation of their antibacterial and in vitro antioxidant activity, Nanosci. Nanotech. Int. Jour. 5(2) (2015) 9-16.

[14] A. Amargeetha, S. Velavan, Green synthesis of silver nanoparticle using Erythrina indica flower extract, J. Nanosci. Tech. 3(4) (2017) 293-295.

[15] B.V. Kero Jemal, Sandeep, S. Pola, Synthesis, characterization, and evaluation of the antibacterial activity of Allophylus serratus leaf and leaf derived callus extracts mediated silver nanoparticles, J. Nanomater. 26 (2017) 1-11.

[16] I. Sondi, B.S. Sondi, Silver nanoparticles as antimicrobial agent: a case study on E. coli as a model for gram-negative bacteria, J. Colloid Interf. Sci. 275 (2004) 177-182.

[17] R. Richards, M.E. Odelola, B. Anderson, Effect of silver on whole cells and spheroplasts of a silver resistant Pseudomonas aeruginosa, Microbios. 39 (2004) 151-157.

[18] M. Vijayakumar, K. Priya, F.T. Nancy, A. Noorlidah, A.B.A. Ahmed, Biosynthesis, characterization and anti-bacterial effect of plant-mediated silver nanoparticles using Artemisia nilagirica, Ind. Crops Prod. 41 (2013) 235-240.

[19] K. Jeeva, M. Thiyagarajan, V. Elangovan, N. Geetha, P. Venkatachalam, Caesalpinia coriaria leaf extracts mediated biosynthesis of metallic silver nanoparticles and their antibacterial activity against clinically isolated pathogens, Ind. Crops Prod. 52 (2014) 714-720.

[20] S.K. Zavriev, L.E. Minchenkova, M. Vorlickova, A.M. Kolchinsky, M.V. Volkenstein, V.I. Ivanov, Circular dichroism anisotropy of DNA with different modifications at N7 of guanine, Biochem. Biophys. Acta 564 (1979) 212-224. 